\title{
EL DÍA DE LA MARIPOSA
}

\section{Juan Antonio Masoliver Ródenas}

En este artículo se sostiene que ha habido una tendencia a ver Los cachorros como una especie de apéndice del cuerpo central de la obra de Mario Vargas Llosa, cuando, en realidad, al margen de sus afinidades, muestra registros originales e irrepetibles. La proliferación de citas en este artículo - explica J. A. Masoliver - trata de compensar las interpretaciones abstractas, cuando no descabelladas, que

Juan Antonio Masoliver (Barcelona, España, 1939) es profesor en el Máster de Creación Literaria en la Universidad Pompeu Fabra y es crítico literario del suplemento Cultura/s de La Vanguardia de Barcelona. Ha sido catedrático de literatura española y latinoamericana de la Universidad de Westminster de Londres y colaborador, entre otras publicaciones mexicanas, de Vuelta, La Jornada Semanal, Letras Libres, Fractal y Crítica. Una amplia recopilación de artículos y ensayos sobre literatura española y mexicana ha sido recogida en Voces contemporáneas (2004) y Las libertades enlazadas (2000) respectivamente. Como narrador ha publicado los libros de relatos $L a$ sombra del triángulo (1996), La noche de la conspiración de la pólvora (2006) y su reciente La calle Fontanills (2010) y las novelas Retiro lo escrito (1988), Beatriz Miami (1991) y La puerta del inglés (2001). Ha traducido entre otros a Cesare Pavese, Giorgio Saviane, Carson McCullers, Djuna Barnes y Vladimir Nabokov. Su obra poética ha sido recogida en Poesía reunida (1999). Posteriormente ha publicado La memoria sin tregua (2002), Sònia (2008) y el libro de poemas en catalán, El laberint del cos (2008). Acantilado acaba de publicar su libro de relatos La calle Fontanills. En la actualidad vive en El Masnou (Barcelona).Tonomasoliver@gmail.com. 
se han hecho de la novela. Se destacan aquí la presencia castradora de la cultura norteamericana y de la educación religiosa, el infantilismo y los símbolos fálicos como parte del enmascaramiento y de la afirmación de la virilidad, la voluntad del grupo de integrar a Cuéllar, la barrera entre el mundo masculino y femenino y la presencia de Teresita Arrarte, que representa el desenmascaramiento definitivo y, con él, la destrucción del protagonista.

$E_{n}$

n el prólogo a la edición de Los jefes/Los cachorros de Seix Barral, Mario Vargas Llosa ${ }^{1}$, posiblemente el mejor analista de su propia obra, expresa "mi sorpresa fue la variedad de interpretaciones que merecían las desventuras de Pichula Cuéllar"2. Una de las razones de esta variedad de interpretaciones, y la más importante, es la propia ambigüedad de la obra que invita a las más descabelladas lecturas, especialmente en una tradición crítica como la nuestra, basada en la exégesis. Por supuesto, mayor es la calidad de un texto mayores son sus posibilidades de interpretación. Es decir, de ir ahondando en los significados más ocultos, de crear una obra abierta como la propone Umberto Eco. Y si yo rechazo aquí el criterio interpretativo o de las múltiples lecturas es porque implicaría manipular unas contradicciones que no nacen del espíritu de la obra (los personajes de Los cachorros lo tienen todo para ser contradictorios) sino de la confusión del autor, algo impensable en la escritura de Vargas Llosa. Propongo aquí, pues, un ahondamiento en los distintos y coherentes significados no siempre del todo visibles pero nunca cerrados. Toda la obra del escritor peruano, incluso aquella en la que llega a las más audaces innovaciones técnicas, está marcada por la claridad. Y en Los cachorros los personajes son contradictorios, pero estas contradicciones no están reñidas con la claridad de los distintos niveles de lectura que el libro nos ofrece. Por otro lado, toda exégesis no tiene que estar guiada por la exhibición (ver lo que otros no han visto) ni por unas ideas que existen en el exégeta pero no en el autor.

${ }^{1}$ Mario Vargas Llosa, "Prólogo a Los jefes/Los cachorros", 2010, pp. 253-258.

2 Ibídem, p. 257. 
Por este motivo, evito comparar las distintas lecturas de las muchas que se han hecho de la obra, aunque no pueda evitar algunas referencias.

Tampoco me propongo comparar Los cachorros con otros escritos de Vargas Llosa, sino hacer una lectura limpia, independiente. Se me pueden hacer objeciones a esta toma de posición, y yo mismo admito que las muchas lecturas que he hecho de la novela las he integrado en esta especie de novela única y siempre inacabada que se inicia, titubeante, con Los jefes ("El cuento de Los jefes al que le perdonaría la vida - ha dicho Vargas Llosa - es 'Día domingo'. La intuición del 'barrio' - fraternidad de muchachos y muchachas con territorio propio, espacio mágico para el juego" ${ }^{3}$ ), y se consolida en Conversación en La Catedral, La tía Julia y el escribidor, el libro de memorias Como pez en el agua y, por supuesto, La ciudad y los perros. Estas coincidencias entre las distintas novelas interesan sobre todo porque crean un mundo familiar, porque señalan el marcado carácter autobiográfico de la obra de Vargas Llosa y porque ponen al descubierto algo que en muchas novelas queda desplazado por la brutalidad del relato - especialmente allí donde la identificación con Julio Ramón Ribeyro es mayor-: la sentimentalidad. No sólo la ternura y la simpatía hacia los personajes más débiles o sensibles, más "castrados", sino también una nostalgia que podríamos definir como joyceana. Como en el caso de Joyce, casi todas las novelas de Vargas Llosa están escritas fuera de su país (Madrid, París, Barcelona, Londres) y hay una necesidad no sólo de regresar a obsesiones que lo fueron de su juventud, sino de recrear a través de los gestos, las costumbres, los recorridos callejeros, los cines o los comercios el mundo de su infancia. Un mundo, por otro lado, que no fue del todo suyo, al que llegaba como un intruso y en el que vivía como "marginado" su peculiar orfandad.

Los principales señuelos de la obra, los que la convierten en una novela única, confirman que la afinidad con otros libros suyos - excepto en la referencia explícita a su infancia - sea anecdótica y hasta engañosa, puesto que los registros son ahora muy distintos. Para empezar, el hecho de que sea una novela corta le exige un planteamiento distinto. Se trata de una novela lineal, pero de una linealidad muy especial, condicionada en realidad por dos hechos centrales: la castración de Cuéllar y la charla de los cuatro amigos o, mejor dicho, miembros del grupo, con Teresita Arrarte. En apariencia es una sucesión que marca el crecimiento

${ }^{3}$ Ibídem, p. 256. 
de los personajes, pero de este crecimiento importa el paso de la infancia a la pubertad, luego a la adolescencia y finalmente a la juventud y la madurez, y la forma en que asumen dichos cambios. La castración marca el desenmascaramiento definitivo de la marginación de Cuéllar, que no pertenece al exclusivo y excluyente barrio de Miraflores, que prefiere los estudios a los deportes y que está poco desarrollado físicamente ("era más chiquito todavía que Rojas"4). El desarrollo de la novela es un continuo conflicto entre enmascaramiento (un rasgo del latinoamericano brillantemente tratado por Octavio Paz en el capítulo "Máscaras mexicanas", de El laberinto de la soledad) y desenmascaramiento, entre marginación e integración. El desarrollo lineal está marcado por los gustos de una clase social privilegiada y carente de la mínima inquietud cultural. Son seres anodinos que brillan solamente por la seguridad que les da el dinero, la pertenencia a un grupo, la seguridad de que nada va a cambiar y los esfuerzos para que nada cambie. Un desarrollo marcado por su condición de varones, como estará marcado el de las mujeres en un mundo todavía más limitado. El proceso es bien claro: "Todavía llevaban pantalón corto ese año, aún no fumábamos"5, es decir, son conscientes de que todavía son unos niños. Y, precisamente porque son unos niños, la castración de Cuéllar todavía no tiene la dimensión trágica que alcanzará más tarde. Con una peculiaridad: como ocurre en Lazarillo de Tormes, también aquí, a pesar de que llegarán a conocer la madurez, a Cuéllar lo pensamos siempre como un niño. Este es uno de los señuelos de la novela, esta especie de inocencia que se mantiene a pesar de todo y que lucha con las nuevas realidades que impone la edad. Por eso para muchos críticos la castración no es un hecho dramático. Para Ángel Esteban — siguiendo la sugerencia de Julio Ortega de que "la castración de Cuéllar adquiere una curiosa ambivalencia, una más irónica normalidad" () - "La actitud con la que se toma la emasculación es tan 'normal', que desdramatiza el drama, y convierte en tema de reto literario, de estilo, la tragedia, hasta llegar a unos límites de adelgazamiento casi esperpénticos"7, y para José Miguel Oviedo, "la truculencia

${ }^{4}$ Mario Vargas Llosa, Los cachorros [1966], edición de Guadalupe Fernández Ariza, Cátedra, Madrid, 2010, p. 56. Esta es la edición seguida en las citas de la obra.

5 Ibídem, p. 35.

6 Julio Ortega, "Los cachorros", 1971, p. 546.

7 Ángel Esteban, “Introducción”, 2010, pp. 50-51. 
deriva de la comicidad grotesca. Esto es una novedad casi absoluta en la obra de Vargas Llosa, una de cuyas más notables ausencias (la otra es la ausencia de Dios) es la del humor"8. Es cierto que hay humor, pero está muy lejos de ser el humor abierto de, por ejemplo, La tía Julia y el escribidor, Pantaleón y las visitadoras, Elogio de la madrastra o Los cuadernos de don Rigoberto, por no hablar de las piezas teatrales.

Es de nuevo el propio Vargas Llosa quien nos da la clave de lo que representa la castración: "soñaba con un relato sobre esta curiosa herida que, a diferencia de las otras, el tiempo irá abriendo en vez de cerrar". Y de este ir abriéndose surge el desarrollo de la novela. De este modo, la castración de Cuéllar no puede desligarse del proceso de integración iniciado desde que el niño llega al Colegio Champagnat, en el que colaborarán el grupo, sus cuatro amigos más cercanos, los padres y, de un modo más envenenado, las muchachas. A todos ellos les conviene mantener un orden social basado en el poder que da el dinero, la virilidad en todas sus expresiones (desde la deportiva a la sexual) y, por supuesto, la feminidad. Frente a ellos y junto a ellos se encuentra Cuéllar, que hace todos los esfuerzos por respetar los códigos que impone esta sociedad, hasta que llega una realidad directamente, fatalmente relacionada con la castración: la sexual. Cuéllar no sólo se adapta a las exigencias del grupo social al que pertenece, sino que incluso acaba por convertirse en una parodia, una forma indirecta de ridiculizar dichos valores. El hecho de que conozcamos su apellido indica ya una identificación, un rasgo individual como lo tienen Teresita Arrarte y Chachito Arnilla, el triángulo del conflicto sexual. En el caso de Cuéllar, su nombre se refiere al atributo masculino del que precisamente carece o, mejor dicho, como nos recuerda Guadalupe Fernández, "Pichula" es un eufemismo que designa el sexo de $\operatorname{los}$ niños ${ }^{10}$ y que sugiere ya la personalidad regresiva que se irá acentuando a lo largo de la novela. Por su parte, Cachito viene de cachar, es decir, follar, chingar o 'coger', y entre el que cacha (Arnilla) y el que no cacha (Cuéllar) está Teresita Arrarte, la única merecedora de nombre y apellido.

${ }^{8}$ José Miguel Oviedo, Mario Vargas Llosa: La invención de una realidad, 1970, p. 174.

9 Mario Vargas Llosa, "Prólogo a Los jefes/Los cachorros", 2010, p. 257.

${ }^{10}$ Guadalupe Fernández Ariza, “Introducción”, 2010, p. 32. 
No sabemos si Cuéllar es distinto al grupo o simplemente es el único individualizado. Sabemos que vive en el 285 de Mariscal Castilla, que antes de llegar a Miraflores vivía en San Antonio, que es buena persona y que es fuerte en los estudios pero débil en deporte, una de las señas de identidad del grupo (aquí del Grupo, es decir, de una clase social concreta): "Buena gente pero muy chancón, decía Choto, por los estudios descuida el deporte"11, "no tenía físico, ni patada, ni resistencia, se cansaba ahí mismo, ni nada"12. Como compensación, su padre, dueño de una fábrica, es un hombre rico y poderoso, acostumbrado a imponer su autoridad: "los hermanos le sobaban de miedo a su viejo. Bandidos, qué le han hecho a mi hijo, les cierro el Colegio, los mando a la cárcel, no saben quién soy yo"13, "una vez, era un escándalo, Hermano, vino su padre echando chispas a la Dirección, martirizaban a su hijo y él no lo iba permitir. Que tuviera pantalones, que castigara esos mocosos o lo haría él"14. El dinero puede comprarlo todo, "le dan más propina que a nosotros cuatro"15, "me compran lo que quiero, nos decía, se los había metido en el bolsillo a mis papás, me daban gusto en todo"16. La autoridad del padre ("y su viejo era el colmo muchacho, hasta cuándo no iba a cambiar, otra palomillada y no le daría ni un centavo más"17) se ve compensada por el cariño de la madre, que roza la cursilería y se convierte en una caricatura de la feminidad ("y ella sonsito, qué importaba, corazoncito, la muchacha se lo cosería y te serviría dentro de la casa, que le diera un beso"18, "y las señoras desde la ventana adiós, adiós corazón"19).

Por lo que se refiere al grupo, carecen de personalidad individual, como se sugiere ya por sus nombres ocultos tras un apodo (Choto, Chingolo) o un diminutivo (Mañuco, de Manuel, Lalo, de Fernando). Sólo en una ocasión se nos dice que salían a la cancha "encabezados por Lalo, el capitán" ${ }^{20}$, pero en realidad carecen de jerarquía y se habla

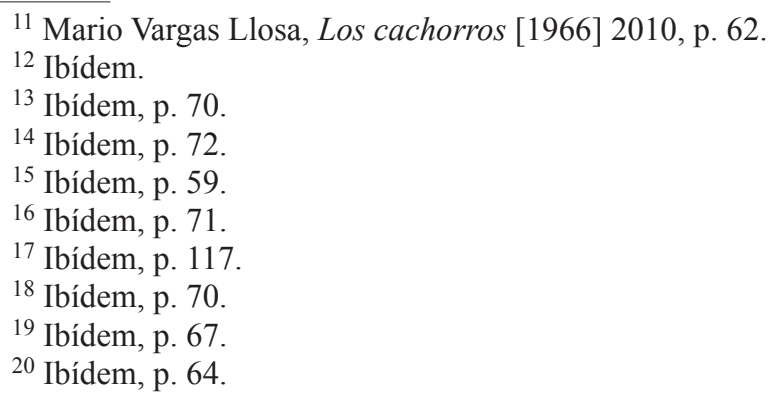


simplemente de "los cuatro". No se les ha elegido a ellos por ninguna razón especial, podría ser cualquiera de los estudiantes del privilegiado Colegio Champagnat o de la privilegiada sociedad limeña. Todos tienen los mismos gustos y la misma educación machista. Por supuesto, todos han recibido una enseñanza mnemotécnica y todos celebran su memoria ("Los Catorce Incas, Cuéllar, decía el Hermano Leoncio, y él se los recitaba sin respirar"21). A la educación y la práctica religiosa ("Esta semana, la misa del domingo, el rosario del viernes y las oraciones del principio y del fin de las clases fueron para el restablecimiento de Cuéllar"22) se añade la patriótica: aprenden de memoria el poema "Mi bandera" de López Albújar y, lógicamente, celebran las Fiestas Patrias. En el Champagnat, "el Hermano Agustín autorizó al equipo de 'Cuarto A' a entrenarse dos veces por semana, los lunes y los viernes, a la hora de Dibujo y Música"23, estableciendo así una clara jerarquía entre el deporte y las asignaturas artísticas.

En el libro no hay ninguna referencia a la política ni a la cultura. Son muchachos de una escandalosa frivolidad, Cuéllar no se distingue de ellos y, cuando lo haga, en plena crisis, será para parodiar la ausencia de verdaderos intereses: "Hablaba de cosas raras y difíciles: la religión (¿Dios que era todopoderoso podía acaso matarse siendo inmortal?, a ver, quién de nosotros resolvía el truco), la política (Hitler no fue tan loco como contaban, en unos añitos hizo de Alemania un país que se le emparó a todo el mundo ¿no?, qué pensaban ellos), el espiritismo..."24. Sus gustos van cambiando a medida que van creciendo: de Tarzán y el Águila Enmascarada a Cantinflas y Tin Tan, a los héroes deportivos (el Conejo Villarán, Boby Lozano, Arnaldo Alvarado), a los cantantes de moda (Pérez Prado o Elvis Presley) y, por supuesto, el modelo para Cuéllar será el James Dean de "Rebelde sin causa", porque rebelde sin causa es él, por mucho que en una de sus crisis parezca entristecerse "de los hombres que ofendieran tanto a Dios, por ejemplo"25, "y también de pena por la gente pobre, por los ciegos, los cojos, por esos mendigos que iban pidiendo limosna en el jirón de la Unión"26.

\footnotetext{
${ }^{21}$ Ibídem, p. 58.

22 Ibídem, p. 63.

${ }^{23}$ Ibídem.

${ }^{24}$ Ibídem, p. 99.

25 Ibídem, p. 114.

${ }^{26}$ Ibídem.
} 
Se ha hablado mucho de la presencia del cómic en Los cachorros, asociado con las referencias al "Águila Enmascarada" y con la onomatopeya, más frecuente en los primeros capítulos. Incluso el accidente de Cuéllar está visto como una aventura: "los vimos desde la escalera y Choto arrancaron a ochenta (Mañuco cien) por hora, tocando bocina y bocina, como los bomberos, como una ambulancia"27. Se ha llegado a decir, puestos a extremar las exégesis, que la novela puede leerse como un cómic. En cualquier caso, estaría integrado en una referencia (sub)cultural mucho más amplia y que afecta a una de las posibles simbologías de la castración: la presencia dominante, castrante de lo norteamericano en la vida limeña y, por extensión, peruana y latinoamericana, y que es inevitable identificar con la cultura machista o directamente fálica, especialmente el tabaco ("Lucky", "Viceroy"), los coches (Chevrolet, Ford, el poderoso Nash) o la ropa de baño (una Jantsen). Quique Rojas "tenía una hembrita mayor que él, de ojazos azules" ${ }^{28}$ y "Chingolo regresó de Estados Unidos casado con una gringa bonita y con dos hijos que apenas chapurreaban español"29; e incluso, paradójicamente, creen encontrar en Estados Unidos la respuesta a su castración: "lo iban a operar, y ellos ¿qué decía Pichulita? ¿de veras te van a operar?, y él como quien no quiere la cosa ¿qué bien, no? Se podía, sí, no aquí sino en Nueva York, su viejo lo iba a llevar"30. El libro está plagado de términos ingleses, reflejo de la presencia dominante de lo norteamericano, una dependencia que se impuso en toda Europa y muy especialmente en América Latina, a través de la publicidad, las películas de Hollywood o los cantantes. Este lenguaje lleno de anglicismos aquí se identifica también con la clase social a la que pertenece el pequeño grupo de amigos: los cracks deportivos, el match, los hamburguer, los milk-shakes, el hot-dog o los salchichas-parties, así como los nombres de los lugares de encuentro: el Cream Rica, el Country Club o el Bowling, espacios reales de la geografía de Miraflores tan meticulosamente reconstruida aquí. Por supuesto, el hecho de que estudien en el Champagnat, fundado por un religioso francés, confirma cómo el prestigio de lo extranjero llega a contradecirse con la educación patriótica que reciben los muchachos.

\footnotetext{
${ }^{27}$ Ibídem, p. 66.

${ }^{28}$ Ibídem, p. 75.

${ }^{29}$ Ibídem, p. 120.

${ }^{30}$ Ibídem, p. 97.
} 
La cronología está marcada por todos estos rasgos (relación con el grupo, exaltación del deporte y de los símbolos fálicos). Si de niños "entre todos los deportes preferían el fútbol" 31 , más tarde, "en esa época, además de los deportes, ya se interesaban por las chicas" 32 . Aprenden a bailar y a fumar al mismo tiempo. En "Tercero A", "todavía llevaban pantalón corto ese año"33 y en Primero de Media "ya usábamos pantalones largos" 34 . En Tercero de Media Lalo es el primero en tener novia, como muy pronto la tendrán todos menos Cuéllar. Terminados los estudios en el Champagnat, Chingolo y Mañuco están en primero de Ingeniería, Lalo en pre-médicas y Choto empieza a trabajar en la "Casa Wiese". Tras su fracasada relación con Teresita, Cuéllar entra a trabajar, a los veintiún años, en la fábrica de su padre. Los amigos se van casando y Cuéllar se va quedando cada vez más marginado.

Hay una tendencia generalizada a ver un deseo inicial de integración de Cuéllar por parte del grupo que muy pronto se va apagando. Para Julio Ortega, junto a la integración está "la marginación ridícula de un castrado por esa misma sociedad (No olvidemos que el perro se llama 'Judas' con justicia poética y también con la ironía que hace de Cuéllar un Cristo traicionado en el Huerto de los Olivos que es el colegio religioso)" ${ }^{\prime 3}$. Empecemos por Judas: ¿a quién ha traicionado? Por supuesto, a toda una clase social y no solamente a Cuéllar, pues a través de sus sucesivas crisis y sus intentos cada vez más fallidos de integración se pone en evidencia una forma de entender la vida, con todas sus trampas. La respuesta inmediata es la simulación, en la que participan todos. El primer paso es vengarse del culpable: "Ellos lo estábamos vengando, Cuéllar, en cada recreo pedrada y pedrada contra la jaula de Judas" ${ }^{36}$, "cojan piedras, vamos a la cancha, a la una, a las dos, a las tres, guau guau guau guau, ¿le gustaba?, que tomara y aprendiera" ${ }^{\prime 37}$. Muerto Judas, es sustituido por "icuatro conejitos blancos! Cuéllar, lléveles lechugas, ah, compañerito, déles zanahorias, cómo te sobaban, cámbieles el agua y él feliz"38.

\footnotetext{
${ }^{31}$ Ibídem, p. 55.

32 Ibídem, p. 74.

33 Ibídem, p. 55.

34 Ibídem, p. 79.

35 Ibídem, p. 195.

36 Ibídem, p. 67.

${ }^{37}$ Ibídem, p. 68.

${ }^{38}$ Ibídem, p. 70.
} 
Cumplida la venganza se inicia un proceso de enmascaramiento en el que participan todos: "los hermanos se enfurecían si los alumnos hablaban entre ellos del accidente [...] Sin embargo ése fue el único tema de conversación en los recreos y en las aulas"39, "y él chist, era un secreto, su viejo no quería, tampoco su vieja, que nadie supiera, mi cholo, mejor no digas nada, para qué" ${ }^{40}$. Se preguntan "¿sería pecado hablar de eso?" 41 y "¿Tere sabrá? Pero nadie se lo preguntaba de frente y él no se daba por enterado con las indirectas" ${ }^{42}$. La solidaridad, la necesidad de negar la realidad de los hechos, es decir, las consecuencias psicológicas y sociales de la castración, llevan a Cuéllar a hacer todos los esfuerzos para integrarse en el grupo y mostrar su virilidad. Ya antes del accidente, el grupo manifestaba esta necesidad de integrarlo, "había que meterlo como sea, decía Lalo, y Chingolo para que esté con nosotros" 43 y Cuéllar, por su parte, "se entrenó tanto en el verano que al año siguiente se ganó el puesto de interior izquierdo" 44 . Después del accidente, cuando la integración es ya un hecho, hay una necesidad de afirmarla, de hacer todo lo posible para que no se rompa la falsa armonía. Cuando regresa al colegio "cosa rara, en vez de haber escarmentado con el fútbol (¿no era por el fútbol, en cierta forma, que lo mordió Judas?) vino más deportista que nunca. En cambio los estudios empezaron a importarle menos" 45 , "se presentaba a los exámenes con promedios muy bajos y los Hermanos lo pasaban, malos ejercicios y óptimo, pésimas tareas y aprobado" 46 y en una inconsciente afirmación de su castración, del mismo modo que Judas es sustituido por cuatro conejitos blancos, los Hermanos le hacen ayudar a misa y cantar en el coro. Del mismo modo, los padres tratan de comprarle con dinero y cariño, "me compran lo que quiero, nos decía, se los había metido al bolsillo a mis papás, me dan gusto en todo" 47 .

La razón principal por las que se trata de negar la castración de Cuéllar es porque la identifican con el afeminamiento. Cuando empie-

\footnotetext{
${ }^{39}$ Ibídem, p. 66.

${ }^{40}$ Ibídem, p. 67.

${ }^{41}$ Ibídem, p. 68.

42 Ibídem, p. 97.

${ }^{43}$ Ibídem, p. 62.

${ }^{44}$ Ibídem.

45 Ibídem, p. 69.

${ }^{46}$ Ibídem.

${ }^{47}$ Ibídem, p. 71.
} 
zan a llamarle Pichulita "al principio Cuéllar, Hermano, lloraba, me están diciendo una mala palabra, como un marica [...] Se quejaba y también se enfurecía, qué has dicho, Pichulita he dicho, blanco de cólera, maricón, temblándole las manos" ${ }^{\prime 4}$, e incluso en plena crisis, poco antes del accidente (¿o suicidio?) que le causará la muerte, cuando le ven salir con rocanroleros de trece o catorce años, "ya está, decíamos, era fatal: maricón". Y también: qué le quedaba, se comprendía, se disculpaba pero hermano, resulta cada día más difícil juntarse con él" 49 , "y Choto a ti te importa mucho el qué dirán, y Mañuco lo rajaban y Lalo si nos ven mucho con él y Chingolo te confundirán" ${ }^{\text {". }}$. Quedan claras las razones por las que tiene que afirmar su virilidad.

Esta afirmación de la virilidad no plantea problemas mientras Cuéllar no tenga que enfrentarse con el sexo opuesto o, sería mejor decir, rival. Cuando fuma, "tenía humo bajo la lengua, y Pichulita yo, que le contáramos a él, ¿habíamos visto?, ocho, nueve, diez, y ahora lo botaba: ¿sabía o no sabía golpear? Y también echarlo por la nariz y agacharse y dar una vueltecita y levantarse sin perder el ritmo" 51 ; y a la hora de beber "icinco capitanes! Seco y volteado, decía Pichulita, así, glu, glu, como hombre, como yo" ${ }^{2}$. Una afirmación de virilidad que cae en lo grotesco sin perder todo lo que tiene de dramática la soledad y la autodestrucción de Cuéllar, un dramatismo que se advierte cuando "poco a poco fue resignándose a su apodo [...] y a veces hasta bromeaba, Pichulita no. ¡Pichulaza ja ja!”53.

"No a las muchachas, claro, sólo a los hombres. Porque en esa época, además de los deportes, ya se interesaban por las chicas" ${ }^{24}$. Es ahora cuando más se esfuerza el grupo por negar la evidencia e integrarlo y cuando se acentúan las crisis y contradicciones de Cuéllar. "Y Lalo: había que ayudarlo, lo decían en serio, le conseguiríamos una hembrita, aunque fuera feíta, y se le quitaría el complejo. Sí, sí lo ayudaríamos, era buena gente, un poco fregado a veces, pero en su caso cualquiera, se le comprendía, se le perdonaba, se le extrañaba" ${ }^{" 55}$. Es decir, aceptan

\footnotetext{
48 Ibídem, p. 72.

${ }^{49}$ Ibídem, p. 118.

${ }^{50}$ Ibídem, p. 119.

${ }^{51}$ Ibídem, p. 78.

52 Ibídem.

53 Ibídem, p. 74.

54 Ibídem.

55 Ibídem, p. 86-87.
} 
la innegable realidad de la castración pero creen que a pesar de todo se puede sustituir por otra realidad y mantener así la integridad del grupo, “¿Por qué no te le caes a alguna muchacha de una vez? Así serían cinco parejas" 56 . Y cuando el sexo opuesto empieza a insinuar que están al tanto del secreto, "ellos déjenlo en paz, salíamos en su defensa, no lo van a convencer, él tenía sus pancitos, sus secretitos, apúrate hermano, mira qué sol, 'La Herradura' debe estar que arde, hunde la pata, hazlo volar al poderoso Ford" 57 , es decir, al símbolo fálico que puede sustituir al sexo. Una afirmación de virilidad que resulta patética en boca de Cuéllar quien, cuando le sugieren que escriba a alguna muchacha proponiéndole ser su amigo, él asiente, le escribiría diciéndole “¿quieres ser mi amiga?, no, qué bobada, quería ser su amigo y le mandaba un beso, sí, eso estaba mejor, pero era corto, algo más conchudo, quiero ser tu amigo y le mandaba un beso y te adoro, ella sería la vaca y yo seré el toro, ja ja. Y ahora firma tu nombre y apellido, y que le hiciera un dibujo, ¿por ejemplo, cuál?, cualquiera, un torito, una florecita, una pichulita" 58 .

Pichula y el grupo al que pertenece establecen una clara diferencia entre el mundo masculino (el toro, la pichula) y el femenino (la flor, la vaca), aunque en el caso de Cuéllar la misoginia propia de las sociedades machistas se acentúa progresivamente. Sin embargo, las mujeres tienen también sus códigos y queda claro que junto a la atracción de los sexos está la rivalidad y la desconfianza, cuando no el claro enfrentamiento. El grupo de muchachas está menos definido que el de los muchachos y tampoco ellas, con la discutible excepción de Teresita, carecen de una personalidad individual: Chabuca Molina, Fina Salas, Pusy Lañas y un largo etcétera, todas ellas con nombres o apodos propios de una clase social. La división entre el mundo de los hombres y el de las mujeres es bien clara. Ellos van al Excelsior, al Ricardo Palma o al Leuro "a ver seriales, dramas impropios para señoritas" 59 . Cuando Cuéllar se siente traicionado porque sus amigos empiezan a salir con chicas, Lalo dice "qué ocurrencia, hermano, la hembrita y los amigos eran dos cosas distintas pero no se oponen, no había que ser celoso" 60 , "que nos esperara en 'El Chasqui' a las dos, dejaríamos a las mucha-

\footnotetext{
56 Ibídem, p. 88.

${ }^{57}$ Ibídem, p. 90.

${ }^{58}$ Ibídem, p. 76.

59 Ibídem, p. 71.

${ }^{60}$ Ibídem, p. 82.
} 
chas en sus casas, lo recogeríamos y nos iríamos a tomar unos tragos, a dar unas vueltas por ahí" ${ }^{\prime \prime 1}$. Ellos intuyen que las muchachas sospechan algo. "Saben, decía Lalo, se cortaba la cabeza que sí, sabían y se hacían las que no, ¿para qué?, para sonsacarles [...]. Tal vez no saben pero cualquier día van a saber, decía Chingolo, y será su culpa, ¿qué le costaba caerle alguna aunque fuera sólo para despistar" ${ }^{\prime 2}$.

El capítulo IV es clave en muchos sentidos, pero sobre todo porque el enmascaramiento llega a su punto más alto, allí donde coincide con el inevitable desenmascaramiento. La llegada de Teresita Arrarte a Miraflores es el revulsivo. Curiosamente, tampoco ella es, como Cuéllar, miraflorina y también conocemos su apellido. Vemos asimismo la solidaridad del grupo, y una transformación en Cuéllar que roza lo ridículo: "la vio y, por un tiempo al menos, cambió. De la noche a la mañana dejó de hacer locuras y de andar en mangas de camisa"63, "parecía el de antes. Qué alegrón, hermano, le decíamos, qué revolucionario verte así" 64 , "De nuevo se volvió sociable, casi tanto como de chiquito. Los domingos aparecía en la misa de doce (a veces lo veíamos comulgar)" "65, "y como para borrar la mala fama que se había ganado con sus aventuras de rocanrolero y comprarse a las familias, se portaba en los cumpleaños y salchicha-parties como un muchacho modelo, llegaba puntual y sin tragos, un regalito en la mano, Chabuquita, para ti, feliz cumplete, y estas flores para tu mamá" ${ }^{\prime 66}$. Incluso está convencido de que puede curarse, "y una noche, luego de una carambola real, a media voz, sin mirarnos: ya está, le iban a operar" ${ }^{67}$. Un sueño de muy corta duración y que se hace más grave precisamente por la entrada de una mujer en su vida. "En qué maldita hora vino Teresita al barrio"68. Dejan toda esperanza para un hipotético futuro, es decir, siguen sin querer enfrentarse a la realidad e incluso decide que seguirá adelante con su relación, hasta que "un día se largaría, le buscaría pleito con cualquier pretexto y pelearía y así todo se arreglaría"69, "hermanos, teníamos

\footnotetext{
${ }^{61}$ Ibídem, p. 94.

62 Ibídem, p. 91.

63 Ibídem, p. 95.

${ }^{64}$ Ibídem, p. 96.

${ }^{65}$ Ibídem.

66 Ibídem, p. 98.

${ }^{67}$ Ibídem, p. 97.

68 Ibídem, p. 98.

${ }^{69}$ Ibídem, p. 105.
} 
razón, era lo mejor, le caeré, estaré un tiempo con ella y la largaré"70. Pero este privilegio masculino del engaño y del implícito desprecio hacia la mujer y sus sentimientos amorosos se tambalea muy pronto. "Ellos, entre ellos, ¿sabrán o se harán?, pero frente a ellas lo defendíamos disimulando"71, "y en el billar: no sabían, qué inocentes, o qué hipócritas, si sabían y se hacían"72.

Llegamos así a la escena más brillante del libro: el encuentro o enfrentamiento entre los cuatro amigos y Teresita, una verdadera exhibición verbal. Si antes he dicho que con la discutible excepción de Teresa el grupo de chicas carece de una personalidad individual es porque, en realidad, ella representa el prototipo y la parodia de lo femenino o, para ser más precisos, del modelo de mujer que exige esa sociedad. Si la madre, con toda su cursilería, representaba la caricatura de la ternura, Teresa representa la caricatura de la coquetería. En esta escena se integran los gestos de la muchacha - "y ella, ojos, boca, naricita", "ay, palmoteando, manitas, dientes, zapatitos", "cintura, tetitas", "un hoyito en los cachetes, pestañitas, cejas" $" 73$ — con la realidad de unas palabras que sugieren que está al tanto de todo: "pero ustedes no le dicen Cuéllar, sino una palabrota fea"74, "por qué tenía ese apodo tan feo"75. De este modo, resulta difícil ver la muerte de Cuéllar como la ve Ángel Esteban, "simbolizada por una escena que la precede, la de la mariposa a la que matan"76 sino como una clara y cruel referencia a su castración, que representa la venganza de lo femenino contra lo masculino, la constatación de que tras todos los símbolos fálicos (los deportes, la bebida, el tabaco, los coches) se esconde una falacia: "que miráramos, juna mariposa!, que corriéramos, la cogiéramos y se la trajéramos"77 "y la mataron, pobrecita", "nunca le decía nada. Y ellos qué cuento, qué mentira, algo le diría, por lo menos la piropearía y ella no, y la enterraría", "no estaba muerta la bandida ise voló!", "cuidado, te vas a manchar", "mejor la botaba, así como estaba, toda apachurrada", "miren, la mariposita, brillaba entre los geranios del jardín ¿o era otro bichito?, la pun-

\footnotetext{
${ }^{70}$ Ibídem.

${ }^{71}$ Ibídem, p. 100.

${ }^{72}$ Ibídem.

${ }^{73}$ Ibídem, p. 101-102.

74 Ibídem, p. 101.

${ }^{75}$ Ibídem, p. 103.

${ }^{76}$ Ibídem, p. 48

${ }^{77}$ Ibídem, p. 101.
} 
ta del dedito, el pie, un taconcito blanco. Pero por qué tenía ese apodo $\tan$ feo",78.

Si hasta ahora el enmascaramiento había permitido una sensación de "normalidad", como si fuese posible vivir en las apariencias, a partir de este momento las chicas le pierden el respeto, "le cantaban 'hasta cuándo, hasta cuándo' para avergonzarlo"79, "cantándole el bolero 'Quizás, quizás, quizas'. Entonces le comenzaron las crisis" 80. Su carácter se vuelve inestable, pasa imprevisiblemente de la violencia al llanto mientras el grupo, siempre solidario, comenta "de Teresa qué coqueta, qué desgraciada, que perrada le hizo. Pero ahora las chicas la defendían", la culpa era toda de Cuéllar, para concluir que era "un maricón"81. Cuéllar se vuelve exhibicionista, corriendo olas, "¿tenían miedo?, ¿de veras?, y Tere ¿él no tenía?" y del mismo modo que cuando el accidente lo veían como una aventura ("arrancaron a ochenta [Mañuco cien] por hora" ${ }^{82}$ ), les parece una extraordinaria aventura ver cómo corre olas “(¿un olón de ocho metros?, decía Lalo, más, ¿cómo el techo?, más, ¿cómo las cataratas del Niágara, entonces?, más, mucho más" ${ }^{33}$, una muestra de que no han salido de su infantilismo y al mismo tiempo de que todavía creen en su hombría, como intenta creérsela él con sus bromas de afirmación fálica: "y si Toni Mella se cortaba cuando se afeitaba, ¿qué pasaba? Se capaba, ja ja, el pobre era tan huevón"84; y en cuanto a las mujeres, “¿bandido, ah sí?, ¿eso decían de mi las rajonas?, no le importaba, las patuquitas se las pasaba, le resbalaban, por aquí" 85 .

El esfuerzo por mantenerlo integrado a pesar de su visible degradación empieza a desmoronarse cuando la evidencia de que no hay salida a la crisis se ha hecho más evidente que la necesidad de mantenerlo en el grupo. Pocas semanas después de su primer accidente grave haciendo el paso de la muerte, en la despedida de soltero de Lalo, ellos quieren bajarse del coche. "Pero él ni de juego, qué teníamos, ¿desconfianza en el trome?, ¿tremendos vejetes y con tanto miedo?, no se vayan

\footnotetext{
${ }^{78}$ Ibídem, p. 102.

${ }^{79}$ Ibídem, p. 103.

${ }^{80}$ Ibídem, p. 105.

${ }^{81}$ Ibídem, p. 106.

82 Ibídem, p. 66.

${ }^{83}$ Ibídem, p. 109-110.

${ }^{84}$ Ibídem, p. 111-112.

${ }^{85}$ Ibídem, p. 93.
} 
a hacer pis" $"$. A partir de ese día, "algo se había fregado entre ellos y él y nunca más fue como antes" ${ }^{97}$. El laconismo al recibir la noticia de su muerte revela cómo el tipo de relación entre los cinco miembros del grupo no se debe a un verdadero sentimiento de amistad sino a la necesidad de respetar unas normas que son sagradas. Con su muerte, llega la liberación. Cuéllar, muerto, ya no representa una amenaza: "pobre, decíamos en el entierro, cuánto sufrió, qué vida tuvo, pero este final es un hecho que se lo buscó" 88 .

Con su muerte no termina la novela, puesto que la vida prosigue su ritmo habitual como proseguirá cuando desaparezcan las ratas en $\mathrm{La}$ peste de Albert Camus. Ha habido un desarrollo lineal, para marcar las distintas edades biológicas de los personajes, hay asimismo una circularidad, puesto que "eran hombres hechos y derechos y ya teníamos todos mujer, carro, e hijos que estudiaban en el Champagnat, la Inmaculada o el Santa María"89, donde vivirán o no una experiencia como la que ellos han vivido y superado, pero hay asimismo un final abierto puesto que nada ha cambiado en sus vidas, es decir, en Lima, en Perú o en todo América Latina, hasta que dejan muy lejos aquella infancia de cachorros y aquella adolescencia de perros: "y comenzábamos a engordar y a tener canas, barriguitas, cuerpos blandos, a usar anteojos para leer, a sentir malestares después de comer y de beber y aparecían ya en sus pieles algunas pequitas, ciertas arruguitas" ${ }^{\circ 0}$. Estamos hablando de ellos, naturalmente, del mundo de los hombres, de los dueños de todos los símbolos fálicos que les permiten ser los dueños y señores de esta sociedad.

Los cachorros es un microcosmos frente al macrocosmos representado por novelas como La ciudad y los perros, Conversación en La Catedral, La Casa Verde o La guerra del fin del mundo. Las innovaciones técnicas son todavía más visibles, precisamente porque nos movemos en un territorio más limitado. Vargas Llosa no nos introduce a los personajes, habla de ellos como si nos fuesen familiares, como si también nosotros formásemos parte de este mundo. No los describe físicamente. Carecen también de vida interior. $\mathrm{O}$, por lo menos, nosotros no podemos

\footnotetext{
${ }^{86}$ Ibídem, p. 120.

${ }^{87}$ Ibídem.

${ }^{88}$ Ibídem, p. 121.

${ }^{89}$ Ibídem.

${ }^{90}$ Ibídem.
} 
penetrar en ella y ellos mismos parecen negarla. Carecen de verdaderos intereses. Sólo nos interesan sus actos y sus palabras, que percibimos simultáneamente. Hay una evocación por parte del escritor, pero no la hay en los personajes, que parecen carecer de pasado, incluso del que nosotros hemos presenciado. Para ellos sólo existe el presente, por eso les parece posible enmascarar la emasculación negando el futuro y todas sus consecuencias. Y sin embargo, eso que parece un instante, un tiempo efímero en el gran tiempo de la historia, queda grabado como algo imborrable. La novela, como ya he dicho y repito a modo de conclusión, está llena de ambigüedades no en el sentido de que sea contradictoria o que sus significados sean vagos o indefinidos, sino de que ofrecen varias lecturas, sin que una niegue a las otras. El título, de forma estricta, sólo puede referirse a los primeros años de los estudiantes del Champagnat $o$, más concretamente, al año en que Cuéllar queda castrado, pero parece sugerir también que todos ellos son infantiles y que nunca han dejado ni dejarán de serlo. Es el infantilismo de la sociedad a la que pertenecen. Cuéllar es consciente de su castración, pero no sabe cómo resolverla y se empeña en negarla. No hay nada de positivo en su rebeldía, porque carece de sentido crítico. Y es el espejo en el que podrían mirarse los demás, pero se niegan a hacerlo para no ver la precariedad sobre la que están montadas sus vidas. El hecho de que se alterne la primera persona del singular y la tercera del plural podría indicar que el propio Vargas Llosa, fiel a sus principios flaubertianos, se presenta como narrador objetivo y distante, pero al mismo tiempo quiere afirmar su presencia, es decir, la presencia del creador y su autoridad sobre la obra creada, autoridad que sin embargo no le permite emitir juicios críticos ni salir de la más rigurosa objetividad. Puede indicar, asimismo, el conflicto del individuo que trata inútilmente de salir de su anonimato, de su condición de ser sin atributos. Es decir, la presencia del narrador es innegable (lo es en cualquier obra de creación) y lo es asimismo la utilización de experiencias autobiográficas. Pero del mismo modo que Joyce, que escribe lejos de su país, reconstruye Dublín con la precisión del científico, sin permitirse la mínima efusión lírica, Vargas Llosa reconstruye un Miraflores escrito desde la distancia, situado en una época determinada (1916 en el Ulises, la década de los cincuenta en Los cachorros) con el máximo rigor. La nostalgia que no puede expresar explícitamente en la novela, la expresa en el mencionado prólogo a la edición de Seix Barral de 1980: "los muchachos y las muchachas estábamos condenados a nuestro 'barrio', prolongación del hogar, reino de la amistad", "el barrio miraflorino era inofensivo, una 
familia paralela, tribu mixta donde se aprendía a bailar, a hacer deportes y a declararse a las chicas. Las inquietudes no eran demasiado elevadas [...]. Acepto que éramos bastante estúpidos, más incultos que nuestros mayores - que ya es decir- y ciegos para lo que ocurría en el inmenso país de hambrientos que era el nuestro" ${ }^{91}$ y del que ha dejado constancia en tantas obras suyas.

Igualmente curioso es que si la novela no está escrita con efusiones nostálgicas, el lector sí percibe aquel mundo como un mundo perdido, irrecuperable sólo a través de la escritura. A eso se debe que podamos leerla como una evocación, como una tragedia, como un melodrama, como una parodia o como una crítica social. En cualquier caso, todo lo que hay de crítica a una sociedad no implica - y esta es la diferencia con la novela naturalista - la imposición de una visión negativa de los personajes. Su frivolidad es casi conmovedora, tal vez porque los vemos más como víctimas que como verdugos, más como irresponsables que como responsables. Todas estas son las razones por las que podemos considerar Los cachorros como una novela única dentro de la producción total del autor, por más que los espacios geográficos y la audaz escritura al servicio de una verdad no descriptiva sino crítica, nos sean familiares, como nos es siempre familiar la voz única de los grandes autores.

\section{REFERENCIAS}

Esteban, Ángel. "Introducción”. En Mario Vargas Llosa, Los cachorros. Los jefes. Edición de Ángel Esteban. Madrid: Austral, 2010.

Fernández Ariza, Guadalupe. "Introducción". En Mario Vargas Llosa, Los cachorros. Edición de Ángel Esteban. Madrid: Austral, 2010.

Ortega, Julio. "Los cachorros". En Julio Ortega y otros, Agresión a la realidad: Mario Vargas Llosa. Las Palmas: Inventarios Provisionales, 1971.

Oviedo, José Miguel. Mario Vargas Llosa: La invención de una realidad. Barcelona: Barral Editores, 1970.

Vargas Llosa, Mario. "Prólogo a Los jefes/Los cachorros" [1959/1966]. En Mario Vargas Llosa, Los cachorros. Los jefes. Edición de Ángel Esteban. Madrid: Austral, 2010.

- Los cachorros [1966]. Edición de Guadalupe Fernández Ariza. Madrid, Cátedra, 2010.

${ }^{91}$ Ibídem. 